\title{
The Eco-Responsibility of Mining Enterprises from Perspective of Eco-Ethics
}

\author{
Miao Ze-hua ${ }^{1, a^{\star}}, \quad$ Chen Yong-hui ${ }^{1, b}$ \\ ${ }^{1}$ Business School, Shijiazhuang University of Economics, Shijiazhuang, Hebei, P.R. China \\ amiaozh1964@126.com , b193859438@qq.com \\ * Corresponding author
}

\begin{abstract}
The construction eco-ethics in mining enterprise, execution of eco-engineering, and assumption of social responsibilities are beneficial not only to the survival and development of the mining enterprise, but also to the structure readjustment, transformation and upgrade of the mining industry and mining enterprises. Mining enterprise is the basis of complex eco-system, and the essence of eco-ethic construction is to bear the responsibilities for shareholders and eco-environment. Therefore, it is necessary for mining enterprise to implement the system of eco-ethic responsibilities, and execute eco-engineering. It requires the mining enterprise to establish social responsibility mode, that is, the mode of cognition $\rightarrow$ influence $\rightarrow$ acceptance $\rightarrow$ consciousness.
\end{abstract}

Keywords: Mining enterprises, Eco-ethics, Eco-responsibility

$$
\begin{gathered}
\text { 生态伦理视阈下矿山企业生态责任探析 } \\
\text { 苗泽华 }{ }^{1, a,{ }^{*}} \text { 陈永辉1,b } \\
\text { 石家庄经济学院商学院, 石家庄, 河北, 中国 } \\
{ }^{a} \text { miaozh1964@126.com, }{ }^{\text {b } 193859438 @ q q . c o m ~} \\
\text { *通讯作者 }
\end{gathered}
$$

中文摘要. 矿山企业树立生态伦理观念, 实 施生态工程, 全面履行社会责任, 不仅有利 于矿山企业自身的持续与发展, 还对矿业及 其相关产业的结构调整、转型与升级具有重 要影响。矿山企业生态伦理建设的实质是矿 山企业作为复合生态系统的基本单位, 切实 承担起维护利益相关者和保护生态环境的 责任。因此, 从生态伦理视阈, 构建矿山企 业社会责任体系, 促进矿山企业实施生态工 程是非常必要的。这要求矿山企业构建 “认
知 $\rightarrow$ 感化 $\rightarrow$ 接受 $\rightarrow$ 自觉” 的社会责任推进模 式。

关键词: 矿山企业; 生态伦理; 生态责任

\section{1. 引言}

随着全球工业化进程, 以及中国工业经 济的迅速发展, 以矿山企业为基础的资源型 企业成为中国经济的重要基础。但矿山企业 在为国民经济创造财富的同时, 也导致了严 峻的环境污染与生态危机。 


\section{2. 生态伦理与社会责任概述}

\section{1 生态伦理及其发展}

生态伦理（Ecological ethics，简写为 Eco-ethics）是关于人与自然关系的伦理, 是生命伦理学 (bio-ethics) 的重要组成部分。 它是人类处理自身及其周围的动物、植物、 矿物及自然环境的关系过程中形成的一系 列道德规范。它确定的是人对自然界和对自 然存在物的道德义务、道德权利和道德关 怀。生态伦理旨在从伦理学的角度为实现全 球的环境保护提供一定的理论依据和道德 动机，并也为一系列的政策制定提供支持。

对生态伦理学的研究, 最早可以追溯到 19世纪早期, 英国的著名功利主义哲学家、 经济学家杰里米 -边沁极力主张把道德范围 扩大到动物范畴。他认为感受苦乐的能力是 获得平等权利的根本特征, 动物也有感受苦 乐的能力。法国著名医学家与哲学家阿尔贝 托・史怀泽主张把伦理的范围扩展到一切动 物和植物, 他认为对一切生物的生命都应当 保持敬畏的态度。1949年，美国伦理学家奥 尔多・利奥波德在他的代表作《沙乡年鉴》 中用艺术的语言描绘了一个荒弃的农场在 一年十二个月中的不同景象, 深刻地提出了 一系列土地环境保护问题以及他的“土地道 德” 观点。该书提出了 “大地伦理学” 思想, 首次阐述了生态中心论。1986年，美国科罗 拉多大学教授, 著名哲学家、环境伦理学家、 被后人誉为 “环境伦理学之父” 的霍尔姆 斯・罗尔斯顿三世在《哲学走向荒野》一书 中提出现代哲学必须从过去只关注人的价 值转向关注自然界的价值。罗尔斯顿认为, 价值是一个金字塔型的结构, 相对于人而言 的价值处于金字塔的顶端，自然物本身的价 值如动物、植物、无机物的价值处于底端, 底端是顶端的基础, 顶端是在底端的基础上 发展而成的，自然界是一个完整的、不可分 割的整体，也是一个生命共同体，自然界这 一生命共同体是价值之源。从这个意义上 讲，人是生命共同体中的一员，对共同体负 有不可推卸的道德责任。罗尔斯顿在其后来 出版的《自然界的价值》、《环境伦理学》 中, 对传统生态伦理提出了挑战, 这对更新 生态伦理意识、重视生物多样性价值、树立
人与自然的整体性关系等具有重要而深远 的意义。

\section{2 社会责任的提出与发展}

早在1924年, 国著名学者奥利弗・谢尔 曼就提出了企业社会责任 (Corporate Social Responsibility, 缩写CSR）的概念。他认为 企业社会责任包含伦理因素。但社会责任这 一概念在数十年中并未受到重视。1953年, 博文发表的《商人的社会责任》标志着企业 社会责任思想的形成。1979年，阿奇B. 卡罗 尔提出了金字塔的企业社会责任, 对企业社 会责任进行了界定。他认为，企业社会责任 基础层次是经济责任, 它主要包括企业盈利 性以及产品合理售价与良好服务等, 第二层 次是法律责任, 它要求企业必须依法行事, 照章纳税, 遵纪守法; 第三层次是伦理责任, 它是指法律没有规定的行为与活动, 这些行 为与活动是社会大众期待, 而企业又能做到 的; 最高层次则是慈善责任, 它是指企业出 于自愿的行为与活动, 如各类捐赠、捐献等。 1984年，弗里曼在著作《战略管理：利益相 关者方法》中提出了利益相关者理论。

自从 20 世纪 50 年代开始, 世界经济和管 理学界对企业社会责任展开了激烈的讨论, 但关于其含义仍众说纷纭, 莫衷一是。企业 对社会到底承担什么责任, 不同组织和学者 的说法不一。世界银行将企业社会责任

（CSR）定义为: “企业与关键利益相关者 的关系、价值观、遵纪守法以及尊重人、社 区和环境有关的政策和实践的集合。”欧盟 则把社会责任定义为: “公司在自愿的基础 上把社会和环境关切整合到其经营运作以 及公司与利益相关者的互动中”。企业社会 责任组织（BSR）界定企业社会责任为：通 过尊崇伦理价值以及对人、社区和自然环境 的尊重, 实现商业的成功。一般来说, 企业 社会责任涉及企业生产运营过程中的每一 个环节, 是其在追求利润最大化过程中所应 承担的社会资产保护及环境保护责任。我国 企业伦理知名学者陈炳富、周祖成指出: “企 业社会责任一般是指企业为所处社会的全 面和长远利益而必须关心、全力履行的责任 和义务, 表现为企业对社会的适应和发展的 参与。”他们认为, 企业社会责任的内容非 常丰富, 既有强制的法律责任（如遵纪守 
法)，也有自觉的道义责任 (如慈善责任)。 综上所述, 企业社会责任就是企业所需要承 担的社会义务, 是企业作为社会公众对利益 相关者及社会、自然环境所需要承担的一种 道德责任。

\section{3. 矿山企业加强生态伦理建设履行生态责 任的必要性}

\section{1 矿山开采与经营所导致的生态环境危 机依然严峻}

矿是蕴藏在地层中可供开采的自然物, 主要包括金属矿物和非金属矿物两大类。现 代汉字 “矿” 就是 “礦” 与 “鑛” 演化并合 二为一了, 《说文解字》: “礦, 铜铁璞石 也。” “鑛, 铁也。又金璞也。”从古人的 解释来看, “鑛” 主要是指金属矿, 而 “礦” 则包含了金属和非金属所有矿物。矿山一般 是指具有开采条件, 能够开采或已经开采的 各类矿床的统称。矿山企业则是包括采矿、 选矿、冶炼及相关生产经营活动的营利性经 济性组织。

改革开放以来, 我国矿业发展迅猛, 为 国民经济与社会发展提供了资源保障。矿山 不仅是矿业的微观单位, 是矿业可持续发展 的基础, 也是资源型产业结构调整与升级中 的重要环节。据有关资料表明, 分布在全国 各地的各类矿山企业已经超过了 12 万个, 其 中大中型矿山企业1.6万多个, 中小型矿业 企业大约11万多个。在全国各省市、自治区, 已经形成了 400 多座矿业城镇, 全国矿业从 业职工人数约 2100 多万, 生活在全国矿业城 镇的人口约 3 亿多人。但随着星罗棋布的矿 山, 遍地开花式的粗放型开采, 矿山生产经 营在为国民经济增加财富的同时, 也以牺牲 生态环境为代价, 酿成了严峻的生态危机。 我国矿业在迅速发展的同时, 产生了大量的 伦理失范及资源、环境、经济与社会问题, 如露天采矿所导致的空气、土壤和水污染; 采矿塌陷所导致的地面开裂、沉降, 以及造 成的耕地损失、景观景貌毁坏与地面道路、 建筑等设施的损毁; 尾矿堆放所导致的环境 污染; 采矿所诱发的地质灾害; 矿山生产经 营活动所导致的其他环境问题等。

\section{2 矿山企业加强生态建设履行生态责任 的必要性}

马克思指出: “在我们这个时代, 每一 种事物好像都包含有自己的反面。我们看 到, 机器具有减少人类劳动和使劳动更有成 效的神奇力量, 然而却引起了饥饿和过度的 疲劳。财富的新源泉, 由于某种奇怪的不可 思议的魔力而变成贫困的源泉。技术的胜 利, 似乎是以道德的败坏为代价换来的。” 英国著名经济学家亚当・斯密在《道德情操 论》一书中, 提出了一种美德叫 “合宜性的 同情心”。美国诺贝尔经济学奖获得者米尔 顿 - 弗里德曼说过: 不读《国富论》不知道 应该怎样才叫 “利已”, 读了《道德情操论》 才知道 “利他” 才是问心无愧的 “利已”。 德国著名哲学家伊曼努尔・康德主张的道德 律令为: “一个人的行为普遍被接受时才是 善的。”

矿山企业作为社会公民承担着道义与 责任。矿山企业必须树立以 “良心、良知、 良能” 等良善价值观为导向的伦理意识, 在 矿山开发的同时切实保护生态环境。矿山企 业生产经营行为之前, “良心” 起着引导与 指挥作用; 在矿山企业生产经营行为中, “良 心”起着督导与监察作用; 在矿山企业生产 经营行为之后, “良心” 起着导向与评价作 用。矿山企业树立生态伦理, 实施生态工程, 构建以生态为价值取向的社会责任体系, 有 利于矿山企业整体素质的提升, 也有利于解 决矿山生态环境治理与恢复等问题, 推进矿 业转型与升级。

\section{4. 矿山企业复合生态系统分析}

\section{1 生态与复合生态系统}

“生态”一词源自于古希腊语“Oikos”, 本义是 “住所”、“栖息地” 等, 后被学者 引申为 “房屋”、“家庭” 等。1866年, 德 国生物学家E.海克尔(Ernst Haeckel)最早提 出生态学的概念。从科学角度来看, 生态一 般是指一切生物的生存状态, 以及生物之间 和生物与所处环境之间相互依存、相互制 约、相生相克、环环相扣的复杂关系。它反 映了自然界诸生物之间、诸主体之间、诸要 素之间错综复杂的关系。从自然环境角度 
看, “生态” 是指自然形成的自然状态, 即 “自然生态”。它是指生物之间及其生物与 环境之间的相互关系与存在状态。生态实质 上反映了复合生态系统中物质、能量、价值、 信息的交换及诸要素的运动状态。

系统是由相互关联的若干组分所构成 的、具有某种特定功能的有机整体。从生态 学和系统科学来看, 人类社会是一个以人的 行为为主导、自然环境为依托、资源流动为 命脉、社会体制为经络的人工生态系统。马 世骏、王如松提出了社会一经济一自然复合 生态系统, 它是由社会系统、经济系统、自 然系统通过复合而组成的一个复杂巨系统, 即所谓的 “社会一经济一自然” 复合生态系 统。马世骏院士认为当今人类赖以生存的社 会、经济、自然是一个系统整体, 社会是经 济的上层建筑, 经济是社会的基本又是社会 联系自然的中介, 自然则是整个社会与经济 的基础。

\section{2 矿山企业的系统分析}

矿山企业是社会一经济一自然复合生 态系统的子系统。矿山企业作为人工子系统 是通过对自身生态理念的设计、推进清洁生 产, 加强环境管理, 促进制药产业链、生态 链的耦合, 从而实现矿山企业子系统与整个 复合生态系统的协调发展。

矿山企业是一个投入产出系统, 它需要 投入人、财、物、技术、信息及相关的自然 资源, 并通过资源转换过程向外部输出各类 矿产品, 并通过市场交换获得回报。从投入 产出关系来看, 矿山企业与用户之间形成了 链式关系。矿产品与市场的关系可用矩阵表 示, 见表1。

表1 矿产品与市场之间的关系

\begin{tabular}{|c|c|c|c|c|}
\hline $\begin{array}{c}\text { 矿产品 } \mathbf{j} \\
\text { 地区 } \mathbf{i}\end{array}$ & $\mathbf{P}^{1}$ & $\mathbf{P}^{2}$ & ....... & $\mathbf{P}^{n}$ \\
\hline$L^{1}$ & $\mathbf{P M}^{11}$ & $\mathbf{P M}^{12}$ & $\ldots . .$. & $\mathbf{P M}^{1 n}$ \\
\hline $\begin{array}{c}L^{2} \\
\ldots\end{array}$ & $\mathbf{P M}^{21}$ & $\mathbf{P M} 22$ & $\cdots \cdots$ & $\mathbf{P M}^{2 n}$ \\
\hline$\cdots$ & $\ldots$ & $\ldots$ & $\ldots . .$. & $\ldots$ \\
\hline $\boldsymbol{L}^{m}$ & $\mathbf{P M}^{m 1}$ & $\mathbf{P M}^{m 2}$ & ....... & $\mathbf{P M}^{m n}$ \\
\hline
\end{tabular}

矩阵中 $\mathrm{P}_{j}$ 表示某矿山企业的第 $\mathrm{j}$ 种产

品, $\mathrm{L}_{\mathrm{i}}$ 表示第 $\mathrm{i}$ 个地区, $\mathrm{PM}_{\mathrm{ij}}$ 表示第 $\mathrm{i}$ 个地区 第 $\mathrm{j}$ 种矿产品的市场。

\section{5. 基于生态视角的矿山企业全过程生态责 任构建}

\section{1 矿山企业全过程生态责任的构成}

在复合生态系统中, 矿山企业不是唯一 独立的个体, 而是与其他个体发生关系的个 体。矿山企业生态责任既包括经济法律层面 的责任（基础性责任），还包括道德层面的 责任高层次责任; 即包括与企业有直接关系 的内部生态责任, 也包括有直接或间接关系 的外部生态责任。事实上, 矿山企业所承担、 履行的生态责任是全过程的。详见表2。

表2 矿山企业全过程生态责任构成

\begin{tabular}{|c|c|}
\hline $\begin{array}{l}\text { 矿山企业不同阶 } \\
\text { 段的责任 }\end{array}$ & $\begin{array}{c}\text { 在不同阶段, 矿山企业所需要承担的具体 } \\
\text { 生态环境责任 }\end{array}$ \\
\hline \multirow{2}{*}{$\begin{array}{l}\text { 矿山开发前的生 } \\
\text { 态环境责任 }\end{array}$} & $\begin{array}{l}\text { 生态环境影响评价及责任。包括矿产资源 } \\
\text { 综合利用、水土保持方案、土地复垦实施 } \\
\text { 方案、矿山地质灾害防治方案、地质环境 } \\
\text { 影响评估和闭矿后生态环境整治与规划 } \\
\text { 等。 }\end{array}$ \\
\hline & $\begin{array}{l}\text { “三同时” 及其责任。包括矿山企业开发 } \\
\text { 及生产经营中防治污染的设施，应当与矿 } \\
\text { 山开发程同时设计、同时施工、同时投产 } \\
\text { 使用。依据有关法规明确矿山企业的责 } \\
\text { 任。 }\end{array}$ \\
\hline \multirow{2}{*}{$\begin{array}{l}\text { 矿山开发中的生 } \\
\text { 态环境责任 }\end{array}$} & $\begin{array}{l}\text { 污染防治责任。包括防治矿山开发活动对 } \\
\text { 大气、水和土壤造成严重的污染以及控制 } \\
\text { 由于开所矿造成的环境噪声污染。这要求 } \\
\text { 矿山企业全面实施清洁生产, 重视绿色设 } \\
\text { 计, 加强绿色矿山建设, 促进矿产资源循 } \\
\text { 环利用。 }\end{array}$ \\
\hline & $\begin{array}{l}\text { 节约与综合利用资源的责任。资源的稀缺 } \\
\text { 性要求矿山企业坚持节约与合理开采自 } \\
\text { 然资源, 坚持开源和节流并重, 把资源节 } \\
\text { 约放在首位, 全面推进 “节能减排”, 切 } \\
\text { 实提高矿山回采率, 加强矿产资源节约与 } \\
\text { 可持续利用。 }\end{array}$ \\
\hline \multirow{2}{*}{$\begin{array}{l}\text { 矿山开发后的生 } \\
\text { 态环境责任 }\end{array}$} & $\begin{array}{l}\text { 废弃矿山环境风险监测责任。包括矿山关 } \\
\text { 闭后的废弃土地、尾矿、尾沙、废石等对 } \\
\text { 矿区大气、水体、土壤、地质环境所可能 } \\
\text { 造成的污染进行监测。 }\end{array}$ \\
\hline & $\begin{array}{l}\text { 矿山生态环境恢复治理的责任。按照闭矿 } \\
\text { 要求, 对矿山 “三废” 进行治理，对矿山 } \\
\text { 所占用的土地进行恢复治理。对有特色的 } \\
\text { 大中型矿山可以建立矿山公园。 }\end{array}$ \\
\hline
\end{tabular}

\section{2 树立社会责任意识, 加强矿山企业伦理 道德建设, 强化生态责任意识}

树立生态环境意识是加强矿山企业生 态伦理与文化建设的核心, 这要求矿山企业 从自身可持续发展和保护生态环境的角度, 建立履行生态责任的长效机制。矿山企业生 态伦理与环境责任建设不是一蹴而就的, 其 
生态责任意识的形成也是一个认知、感化、 接受, 到自觉的过程。如图1所示。

\begin{tabular}{|c|c|c|c|c|}
\hline \multicolumn{4}{|c|}{$\begin{array}{l}\text { 矿山企业自觉履行 } \\
\text { 生态环境责任 }\end{array}$} & $\begin{array}{l}\text { 矿山企业的行为体现了以 “生态为中心” } \\
\text { 的道德理念, 全面履行社会责任, 自觉履 } \\
\text { 行环保责任, 勇担慈善重任等。 }\end{array}$ \\
\hline \multicolumn{3}{|c|}{$\begin{array}{l}\text { 矿山企业全面接受 } \\
\text { 生态环境责任观念 }\end{array}$} & & $\begin{array}{l}\text { 企业重视其开采与经营中的环境责任以及 } \\
\text { 伦理与文化建设, 树立了建设绿色矿山理 } \\
\text { 全面推进清洁生产, 重视资源综合利用。 }\end{array}$ \\
\hline \multicolumn{2}{|c|}{$\begin{array}{l}\text { 矿山企业对生态环 } \\
\text { 境责任有一定认知 }\end{array}$} & \multicolumn{3}{|c|}{$\begin{array}{l}\text { 矿山企业对生态环境保护有一定认识, 基本能够遵 } \\
\text { 循矿山企业的从业道德, 基本上按照有关法规进行 } \\
\text { 矿山开采与经营, 关注利益相关者的诉求。 }\end{array}$} \\
\hline 不接受生 & 要求, & & & $\begin{array}{l}\text { 生态环境保护的意识, 或者漠视有关法规 } \\
\text { 监相关者的诉求, 一味追求 “利润最大 } \\
\text { “三废”, 肆意污染生态环境等。 }\end{array}$ \\
\hline
\end{tabular}

图1 矿山企业对社会责任认知及履行阶梯模型 要促进矿业的可持续发展, 加强生态伦 理建设是基础, 全过程地履行生态责任是途 径。具体地说: (1) 深入调查河北省矿山 企业生态责任的履行状况，从政策与法规层 面构建矿山企业履行生态责任的推进模式 与长效机制。（2）系统研究矿山企业生态 伦理与生态责任的关系, 建立以“生态主义” 为价值导向的伦理体系与文化。(3) 加强 生态认知, 运用经济学、管理学、生态学和 系统论等理论与方法, 设计矿山企业全生命 周期过程, 制定不同阶段的生态责任任务与 职责，规划矿山企业生态工程目标与措施。

（4）把矿山企业履行生态责任与矿山企业 转型升级有机结合起来,一手抓矿山企业伦 理与文化建设, 形成自觉履行全过程生态责 任的文化氛围; 另一手抓自主创新体系, 全 面推进矿山企业转型升级, 实现矿山企业经 济、生态和社会效益的协调发展。

\section{6. 结束语}

总之, 矿山企业不仅要树立生态伦理观 念, 建立全过程的生态环境责任体系, 而且 必须形成一个良性的长效的企业生态责任 建设与履行的长效机制。矿山企业要根据生 态责任, 设计并实施生态工程, 形成具有可 操作性的措施, 全面推进矿山企业转型与升 级。
致谢

本文为《河北省矿山生态工程及资源型 产业转型升级研究》 (项目编号: 14454217D）的阶段性研究成果之一。

\section{References}

[1] B. Na, M. Zehua, Foreign Research Review on Corporate Ecological Responsibility from Micro View, Ecological Economy, vol.8, pp.105-110, 2013.

[2] G. Bridge, Mapping the Bonanza: Geographies of Mining Investment in an Era of Neoliberal Reform, The Professional Geographer, vol.56, No.3, pp. 406-421,2004.

[3] Donna J. Wood, Corporate Social Performance Revisited, The Academy of Management Review, vol. 16, No.4, pp.691-718, 1991.

[4] J.C.Henderson, Corporate Social Responsibility and Tourism: Hotel Companies in Phuket, Thailand, after the Indian Ocean Tsunami, Hosp Manage, vol. 26, pp.228-239, 2007.

[5] Warhurst, A and Gavin Bridge, Financing environment performance strategies, Mining Finance, vol. 4, pp.54-56, 2007.

[6] L. Yuqiang, Current situation and prospect of green mine construction, Conservation and Utilization of Mineral Resources, vol. 5-6, pp.4-8, 2011.

[7] Q. Fansheng, Building the green mine for the development of green mining, China Mining Magazine, vol. 18, No.8, pp.4-6, 2009.

[8] A. B. Caroll, A Three--dimensional conceptual model of corporate social performance, Academy of Management Review, No.4, 1979.

[9] W. Shijin, P. Qing, The Environmental Responsibility of Mining Enterprise and Its Execution, Journal of Jiangxi University of Science and Technology, vol. 31, No.4, pp.10-12, 2010. 